\title{
DETERMINAÇÃO ESPECTROFOTOMÉTRICA EM FLUXO DE CLORO EM ÁGUA USANDO CÉLULA DE LONGO CAMINHO ÓPTICO E MULTICOMUTAÇÃO
}

\author{
Fernanda Helena Salami, Viviane Gomes Bonifácio e Orlando Fatibello-Filho* \\ Departamento de Química, Universidade Federal de São Carlos, CP 676, 13560-970 São Carlos - SP, Brasil \\ Luiz Humberto Marcolino-Jr. \\ Departamento de Química, Universidade Federal do Paraná, CP 19081, 81531-990 Curitiba- PR, Brasil
}

Recebido em 1/2/08; aceito em 10/7/08; publicado na web em 2/12/08

\begin{abstract}
SPECTROPHOTOMETRIC FLOW DETERMINATION OF CHLORINE IN WATER USING A LONG PATHLENGTH OPTIC CELL AND MULTICOMMUTATION. A multicommuted method for determination of chlorine in water samples using a 100-cm cell was developed. In this method, orto-Tolidine reacts with chlorine and the product was monitored at $438 \mathrm{~nm}$. The analytical curve for chlorine was linear in concentration range from $1.34 \times 10^{-6}$ to $2.01 \times 10^{-5} \mathrm{~mol} \mathrm{~L}^{-1}$ with a detection limit of $9.40 \times 10^{-8} \mathrm{~mol} \mathrm{~L}^{-1}$. A sampling rate of $45 \mathrm{~h}^{-1}$ and a RSD of $1.0 \%(\mathrm{n}=15)$ were obtained. The method was applied with success for chlorine determination in six water samples.
\end{abstract}

Keywords: flow analysis; chlorine; long pathlength spectrophotometry.

\section{INTRODUÇÃO}

Os processos de desinfecção das águas têm como objetivo a destruição ou inativação de organismos patogênicos, causadores de doenças, ou de outros organismos indesejáveis. ${ }^{1}$

Há citações do uso pioneiro de cloração em águas para abastecimento público, em 1896, experimentalmente em Louisiville (Estados Unidos); em 1897, na Inglaterra e, em 1902, na Bélgica, pela aplicação da cal clorada (hipoclorito de sódio e hipoclorito de cálcio) juntamente com sais de ferro como coagulantes. ${ }^{2}$

O cloro livre, termo que designa o ácido hipocloroso e o íon hipoclorito, é utilizado em estações de tratamento de águas de abastecimento público, ${ }^{3}$ e isso se deve ao seu elevado poder oxidante e biocida, principalmente do ácido hipocloroso. ${ }^{4}$

Em contato com a água, o cloro hidrolisa-se, formando os íons hidrogênio e cloreto e o ácido hipocloroso.

$\mathrm{Cl}_{2(\mathrm{aq})}+\mathrm{H}_{2} \mathrm{O}_{\text {(liq) }} \rightleftharpoons \mathrm{HOCl}_{(\mathrm{aq})}+\mathrm{H}^{+}{ }_{(\mathrm{aq})}+\mathrm{Cl}^{-}{ }_{(\mathrm{aq})}$

Como pode ser observado na Equação 2, o ácido hipocloroso está em equilíbrio com o íon hipoclorito. ${ }^{5}$

$$
\mathrm{HOCl}_{(\mathrm{aq})} \stackrel{\mathrm{Ka}}{\rightleftharpoons} \mathrm{OCl}_{(\mathrm{aq})}^{-}+\mathrm{H}_{(\mathrm{aq})}^{+}
$$

$\mathrm{K}_{\mathrm{a}}=\frac{\left[\mathrm{ClO}^{-}\right]\left[\mathrm{H}^{+}\right]}{[\mathrm{HClO}]}=2,88 \times 10^{-8} \mathrm{~mol} \mathrm{~L}^{-1}$

$\left(\mathrm{pK}_{\mathrm{a}}=7,54\right)$

sendo $\mathrm{K}_{\mathrm{a}}$ a constante de dissociação do ácido hipocloroso a $20^{\circ} \mathrm{C}$.

$\mathrm{O}$ ácido hipocloroso $(\mathrm{HOCl})$ possui uma atuação bactericida mais eficiente que o íon hipoclorito $\left(\mathrm{OCl}^{-}\right)$. Isso se deve à maior permeabilidade da membrana celular ao $\mathrm{HOCl}$, por ser uma molécula neutra, que ao íon $\mathrm{OCl}^{-}$.

A Portaria 518 do Ministério da Saúde exige que a água para consumo humano apresente concentrações iguais ou superiores a 0,2

*e-mail: bello@ufscar.br mg L ${ }^{-1}$ de cloro residual livre. ${ }^{6}$

Neste trabalho, a determinação do cloro envolve a rápida oxidação da orto-Tolidina, formando uma imino-quinona (Figura 1).
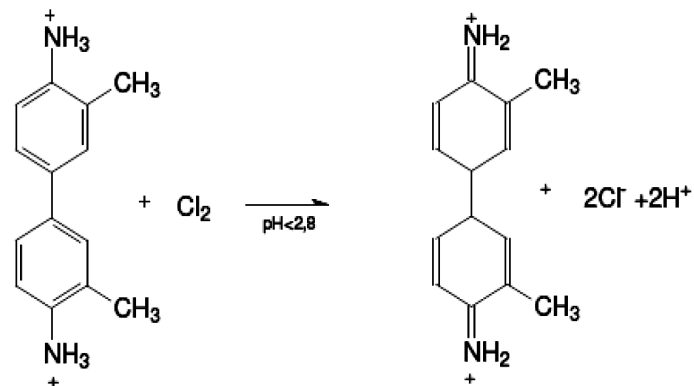

Figura 1. Oxidação da orto-Tolidina, formando uma imino-quinona

O sistema de análise por injeção em fluxo, com o uso da multicomutação, é um procedimento analítico que apresenta vantagens, como automação da manipulação de soluções com fluxo intermitente, descartando-se alguns tipos de contaminação; minimização do consumo de reagentes e amostras, uma vez que somente quantidades necessárias para a determinação são deslocadas para o fluxo transportador; aumento da freqüência de amostragem; simplicidade e, baixo custo de instrumentação. ${ }^{7}$

Métodos analíticos espectrofotométricos são caracterizados como simples e robustos, envolvendo instrumentação de baixo custo. Porém, algumas aplicações exigem maior sensibilidade. Algumas alternativas para atender a tais quesitos têm sido estudadas, tais como o aumento do caminho óptico das células de medidas, devido ao conseqüente aumento no número de espécies absorventes que interagem com o feixe de radiação. ${ }^{8,9} \mathrm{O}$ guia de radiação por distâncias relativamente longas é eficientemente efetuado empregando-se cabos de fibras ópticas.

Há trabalhos na literatura em que se usa a célula de longo caminho óptico na determinação de peróxido de hidrogênio, ${ }^{10}$ fenol, ${ }^{11}$ benzeno, tolueno, etilbenzeno e xilenos (BTEX), ${ }^{12}$ cloreto, ${ }^{13}$ cromio (VI) e molibdênio (VI),${ }^{14}$ Rodamina $\mathrm{B},{ }^{15}$ ferro II, ${ }^{16}$ cobre, ${ }^{17}$ amostras ambientais ${ }^{18}$ e nitrito, ${ }^{19}$ entre outros. Isso mostra 
que o aumento do percurso analítico é de grande utilidade para a determinação de alguns compostos presentes em concentrações da ordem de $\mu \mathrm{g} \mathrm{L}^{-1}$, como é o caso de fenóis, surfactantes, alguns cátions metálicos, etc.

\section{PARTE EXPERIMENTAL}

\section{Equipamentos}

Para este sistema, utilizou-se uma bomba peristáltica Ismatec de 12 canais, modelo 7618-50, com tubos de propulsão de Tygon para o transporte das soluções, três válvulas solenóides (NResearch, West Caldwell,161T031), tubos de polietileno (0,8 $\mathrm{mm}$ d.i.). Foi utilizada uma confluência de acrílico com quatro vias, para entrada e saída de reagente, amostra e solução carregadora, e uma célula de Teflon AF2400, de $100 \mathrm{~cm}$ de caminho óptico e volume interno de $250 \mu \mathrm{L}$ (Ocean Optics), revestida internamente com sílica, para obtenção dos sinais analíticos. Utilizaram-se cabos de fibra óptica com fenda de $50 \mu \mathrm{m}$ para a conexão entre a célula e o espectrofotômetro, e fenda de $600 \mu \mathrm{m}$ para conexão entre a célula e a fonte de radiação.

Para controle e aquisição de dados, foi utilizado um microcomputador Pentium 4, equipado com uma interface eletrônica (Advantec PCI-1710A). Para medida dos sinais, fez-se uso de uma lâmpada de tungstênio-halogênio e um espectrofotômetro com arranjo linear de 2048 fotodetectores do tipo CCD (Charge Coupled Devices), da Ocean Optics-modelo USB-2000. O programa para controle do módulo de análise e aquisição de dados foi desenvolvido em linguagem $\mathrm{C}++$.

\section{Reagentes e soluções}

Todas as soluções foram preparadas com a utilização de água desionizada.

A solução transportadora de ácido fosfórico $\left(\mathrm{H}_{3} \mathrm{PO}_{4}\right)$ p.a. 1,0 mol L ${ }^{-1}$ foi preparada pela diluição de $17 \mathrm{~mL}$ desse ácido com água desionizada, num balão de $250 \mathrm{~mL}$, sendo padronizada com solução padrão de hidróxido de sódio $0,50 \mathrm{~mol} \mathrm{~L}^{-1}$.

Para preparar a solução do reagente orto-Tolidina, foram pesados 0,0250 g do reagente, que foi diluído com água desionizada, num balão de $25 \mathrm{~mL}$. Dessa solução foi retirada uma alíquota de $15 \mathrm{~mL}$, que foi transferida para um balão volumétrico de $50 \mathrm{~mL}$, sendo o volume completado com a solução transportadora

As 6 amostras de águas de abastecimento estudadas foram coletadas em seis bairros diferentes da cidade de São Carlos-SP. Essas amostras foram analisadas, de acordo com o método usado pelas estações de tratamento de água, inclusive a CETESB $^{20}$ (kit DPD colorimétrico), e pelo método estudado (FIA-LCO). As análises foram feitas no mesmo dia em que as amostras chegaram ao laboratório, evitando-se, assim, a perda de cloro por evaporação.

\section{Procedimento}

O diagrama do sistema em fluxo do módulo de análises empregado para determinação de cloro em amostras de água de abastecimento está representado na Figura 2. Quando as válvulas são acionadas (ligadas), as soluções de amostra e de reagente são direcionadas para o fluxo transportador através da confluência, e, ao se encontrarem, reagem com auxílio da bobina helicoidal, onde é formado um complexo de coloração amarela que é encaminhado para a célula de longo caminho óptico $(100 \mathrm{~cm})$. Na célula, um feixe de radiação proveniente da fibra óptica atravessa a solução, resultando num sinal analítico proporcional à concentração de cloro na amostra.

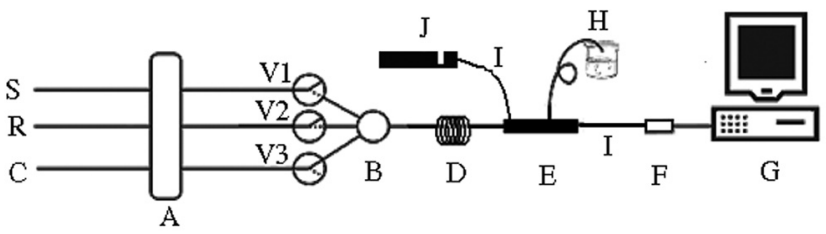

Figura 2. Diagrama do sistema em fluxo, para determinação de cloro em águas de abastecimento: (C) solução carregadora de ácido fosfórico 1,0 mol $L^{-1}$; (S) amostra; (R) solução de reagente (orto-Tolidina); (A) bomba peristáltica; (V1), (V2) e (V3) válvulas solenóides de três vias; (B) confluência; (D) bobina helicoidal $(40 \mathrm{~cm}) ;(E)$ célula de longo caminho óptico (100 $\mathrm{cm}) ;(F)$ espectrofotômetro $(\lambda=438 \mathrm{~nm}) ;(G)$ computador; $(H)$ descarte, $(I)$ fibras ópticas para transporte da radiação e $(J)$ fonte de radiação (lâmpada de tungstênio-halogênio). As linhas tracejadas representam os trajetos do fluxo, quando as válvulas são ligadas

\section{RESULTADOS E DISCUSSÃO}

\section{Estudos preliminares}

Vários parâmetros foram estudados e otimizados, a fim de se obter os melhores resultados para o sistema.

A Tabela 1 mostra os parâmetros físicos e químicos avaliados pelo sistema proposto, (FIA-LCO), para determinação de cloro em amostras de água de abastecimento.

Tabela 1. Parâmetros otimizados do sistema FIA-LCO, para determinação de cloro em águas de abastecimento

\begin{tabular}{lcc}
\hline Parâmetros & $\begin{array}{c}\text { Intervalo } \\
\text { estudado }\end{array}$ & $\begin{array}{c}\text { Valor } \\
\text { selecionado }\end{array}$ \\
\hline Solução de $\mathrm{H}_{3} \mathrm{PO}_{4} / \mathrm{mol} \mathrm{L}^{-1}$ & 0,1 a 1,2 & 1,0 \\
Vazão das soluções / $\mathrm{mL} \mathrm{min}^{-1}$ & 0,7 a 1,3 & 1,1 \\
Tempo de Amostragem / s & 1,0 a 2,0 & 1,2 \\
Bobina helicoidal / cm & 20 a 60 & 40 \\
Concentração de o-Tolidina / $\mathrm{mol} \mathrm{L}^{-1}$ & $3 \times 10^{-4}$ a $3 \times 10^{-6}$ & $3 \times 10^{-5}$ \\
\hline
\end{tabular}

Avaliou-se a influência da concentração da solução transportadora de ácido fosfórico $\left(\mathrm{H}_{3} \mathrm{PO}_{4}\right)$ sobre o sinal analítico. De acordo com os resultados, a melhor concentração de ácido fosfórico foi de 1,0 mol $\mathrm{L}^{-1}$, sendo empregada no restante do trabalho experimental.

A vazão foi avaliada no intervalo de 0,7 a $1,4 \mathrm{~mL} \mathrm{~min}^{-1}$. O sinal de absorbância aumentou gradativamente com a vazão, até $1,3 \mathrm{~mL}$ $\mathrm{min}^{-1}$; depois, o sinal analítico permaneceu constante em vazões superiores. A vazão selecionada foi de $1,1 \mathrm{~mL} \mathrm{~min}^{-1}$, uma vez que essa vazão proporcionou alta magnitude do sinal analítico, boas precisão e exatidão e estabilidade da linha base.

O tempo de amostragem estudado foi de 1,0 a 1,5 s. O sinal analítico aumentou gradativamente com o tempo de amostragem. O tempo de $1,2 \mathrm{~s}$ foi selecionado, pois se obteve um melhor compromisso entre sinal analítico, precisão, exatidão e estabilidade da linha base.

O comprimento da bobina helicoidal foi avaliado num intervalo de comprimento de 20 a $60 \mathrm{~cm}$. Os sinais de absorbância foram próximos, o comprimento de $40 \mathrm{~cm}$ foi selecionado por proporcionar boa homogeneização da amostra com o reagente, além de alta frequiência de amostragem.

Foi também avaliado o efeito da concentração do reagente ortoTolidina sobre o sinal analítico no intervalo de concentração de $3 \times 10^{-4}$ a $3 \times 10^{-6} \mathrm{~mol} \mathrm{~L}^{-1}$. O sinal analítico não variou de maneira significativa; 
então, o valor de concentração de $3 \times 10^{-5} \mathrm{~mol} \mathrm{~L}^{-1}$ foi selecionado. Em concentrações menores desse reagente cromogênico e concentrações de cloro em água menores que $0,3 \mathrm{mg} \mathrm{L}^{-1}$ obtiveram-se um sinal analítico não significativo e desvios padrão elevados.

\section{Interferentes em potencial}

Foram avaliados alguns íons $\left(\mathrm{SO}_{4}^{2-}, \mathrm{Ac}^{-}, \mathrm{NO}_{3}^{-}, \mathrm{K}^{+}, \mathrm{Na}^{+}, \mathrm{NH}_{4}^{+}\right.$, $\mathrm{Ca}^{2+}, \mathrm{Mg}^{2+}, \mathrm{Ba}^{2+}$ e $\mathrm{Fe}^{2+}$ ) presentes em águas, que podem interferir na determinação de cloro, em concentração dez vezes maior e na mesma concentração que o cloro $\left(1,0 \mathrm{mg} \mathrm{L}^{-1}\right)$. Nenhum desses íons apresentou interferência significativa.

\section{Parâmetros analíticos e aplicações}

O estudo da repetibilidade (Figura 3) foi feito para 15 determinações sucessivas $(\mathrm{n}=15)$ de cloro $\left(1,0 \mathrm{mg} \mathrm{L}^{-1}\right)$ e mostrou que este método apresentou boa repetibilidade, com um desvio padrão relativo de $1,0 \%$ e freqüência analítica de 45 determinações por hora.

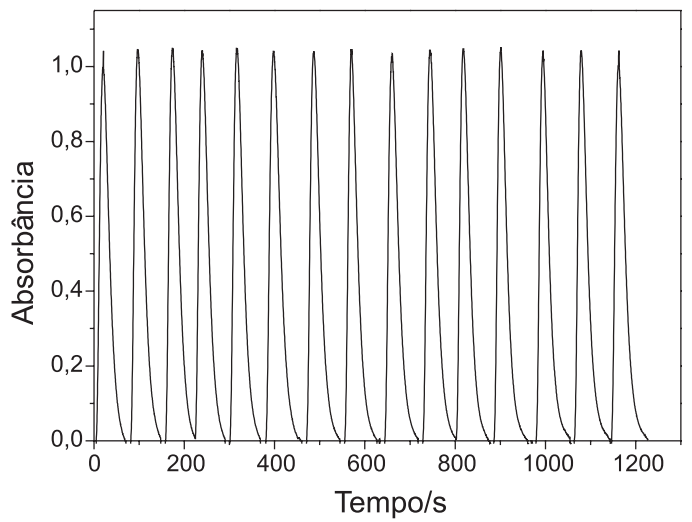

Figura 3. Sinais transientes obtidos pelo estudo da repetibilidade do cloro (1,0 $\left.\mathrm{mg} \mathrm{L}^{-1}\right)$, para 15 determinações sucessivas, $(R S D=1,0 \%)$

Na Figura 4, observam-se os sinais transientes obtidos para soluções de referência de cloro e para amostras de água de abastecimento. Da esquerda para direita: soluções padrão de cloro, em triplicata, variando de 0,1 a 1,5 $\mathrm{mg} \mathrm{L}^{-1}, 6$ amostras de água de abastecimento

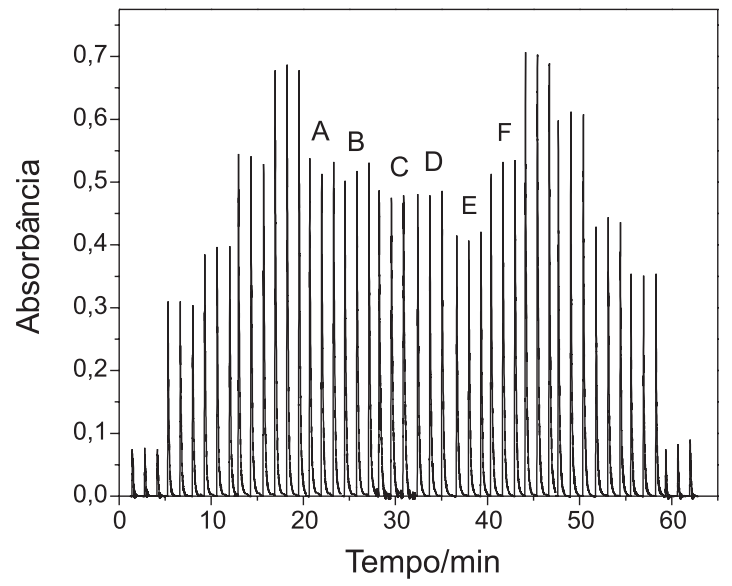

Figura 4. Sinais transientes das soluções padrão e das amostras. Da esquerda para direita: soluções padrão de cloro, em triplicata, variando de 0,1 a 1,5 mg $L^{-1}$; seis amostras de água de abastecimento $(A, B, C, D, E$ e F), em triplicata, $e$, novamente, a soluções padrão de cloro, em concentrações decrescentes
(A, B, C, D, E e F), em triplicata, e, novamente, as soluções padrão de cloro, em concentrações decrescentes.

Adotando as condições fornecidas na Tabela 1, a curva analítica $(\mathrm{r}=0,9992)$ apresentou boa linearidade no intervalo de concentração de 0,1 a $1,5 \mathrm{mg} \mathrm{L}^{-1}$ de cloro $\left(1,34 \times 10^{-6}\right.$ a $\left.2,01 \times 10^{-5} \mathrm{~mol} \mathrm{~L}^{-1}\right)$, com um limite de detecção de $7,0 \times 10^{-3} \mathrm{mg} \mathrm{L}^{-1}\left(9,40 \times 10^{-8} \mathrm{~mol} \mathrm{~L}^{-1}\right)$, um consumo de reagente orto-Tolidina de $0,26 \mu \mathrm{g}$ por determinação $(30 \mu \mathrm{L}$ de solução), gerando um volume de $60 \mu \mathrm{L}$ de resíduo por determinação. O estudo de adição e recuperação foi feito para as 6 amostras de água de abastecimento, obtendo-se uma recuperação que variou de 96,8 a $104,6 \%$, indicando que não houve interferência significativa da matriz das amostras nas determinações do analito.

A Tabela 2 mostra os resultados obtidos para a determinação de cloro em águas de abastecimento, empregando-se o método da CE$\operatorname{TESB}^{20}$ (Kit DPD colorimétrico) e o método proposto (FIA-LCO).

Tabela 2. Resultados obtidos para a determinação de cloro $\left(\mathrm{mg} \mathrm{L}^{-1}\right)$ em águas de abastecimento, empregando-se o método da CETESB (kit DPD colorimétrico) e o proposto (FIA-LCO) neste trabalho

\begin{tabular}{lccc}
\hline Amostras & $\begin{array}{c}\text { Kit DPD } \\
\text { colorimétrico }\end{array}$ & $\begin{array}{c}\text { Método proposto } \\
\text { FIA-LCO }\end{array}$ & Er\% \\
\hline 1 & $0,80 \pm 0,02$ & $0,83 \pm 0,01$ & 3,7 \\
2 & $0,30 \pm 0,04$ & $0,29 \pm 0,01$ & $-3,3$ \\
3 & $0,75 \pm 0,04$ & $0,86 \pm 0,01$ & 14,6 \\
4 & $0,30 \pm 0,03$ & $0,32 \pm 0,01$ & 6,6 \\
5 & $0,75 \pm 0,04$ & $0,89 \pm 0,03$ & 18,6 \\
6 & $0,30 \pm 0,02$ & $0,29 \pm 0,01$ & $-3,3$ \\
\hline
\end{tabular}

Realizou-se o estudo da concordância ${ }^{21}$ entre os métodos, e observou-se que o método proposto (FIA-LCO) apresentou resultados semelhantes aos da CETESB (Kit DPD colorimétrico), com um nível de confiança de $95 \%$.

A Tabela 3 apresenta algumas figuras de mérito obtidas empregando-se o método estudado (FIA-LCO) e as figuras de mérito encontradas em alguns artigos publicados, para a determinação de cloro em amostras de água de abastecimento.

O método proposto apresentou um limite de detecção menor e um desvio padrão relativo (estudo da repetibilidade) menor que aqueles obtidos nos métodos descritos na literatura. ${ }^{22,23}$

A sensibilidade do método proposto foi maior que as obtidas nos métodos desenvolvidos por Pobozy et al. ${ }^{22} \mathrm{e}$ March et al. ${ }^{23} \mathrm{e}$ equivalente àquela obtida por Icardo et al.. ${ }^{24}$ Uma melhora de sensibilidade e/ou da linearidade poderiam ser obtidas aumentando-se o tempo de amostragem e a concentração do reagente (orto-Tolidina). Porém, com o objetivo de se utilizar menor concentração de reagente e, conseqüentemente, menor geração de efluentes, optou-se por manter a sensibilidade e a linearidade obtidas. Outro fator que contribuiu para essa decisão foi que o intervalo de concentração da curva analítica obtida, está no intervalo de concentrações estabelecido pela CETESB

Na determinação de cloro empregando-se o método proposto, utilizou-se um volume de $30 \mu \mathrm{L}$ de reagente $\left(3 \times 10^{-5} \mathrm{~mol} \mathrm{~L}^{-1}\right)$ por análise, enquanto que no sistema desenvolvido por March et al..$^{22}$ foi empregado um volume de $50 \mu \mathrm{L}\left(6,3 \times 10^{-3} \mathrm{~mol} \mathrm{~L}^{-1}\right)$. Em ambos os procedimentos, para a determinação de cloro, foi utilizada solução de orto-Tolidina, sendo que quanto menor a concentração ou volume do reagente, por determinação, menor será o impacto ambiental causado pelo efluente gerado. Cabe enfatizar que o efluente gerado no trabalho foi encaminhado para a Unidade de Gestão de Resíduos (UGR) da UFSCar. 
Tabela 3. Tabela comparativa das figuras de mérito, obtidas no método desenvolvido e em outros encontrados na literatura, para determinação de cloro em águas de abastecimento

\begin{tabular}{lcccc}
\hline Figuras de mérito & Icardo et al. ${ }^{22}$ & March et al. ${ }^{21}$ & Pobozy et al. ${ }^{20}$ & Método proposto \\
\hline Linearidade / mol L & $6,71 \times 10^{-7} \mathrm{a} 1,74 \times 10^{-5}$ & 0 a $6,71 \times 10^{-5}$ & $1,34 \times 10^{-6}$ a $1,34 \times 10^{-5}$ & $1,34 \times 10^{-6} \mathrm{a} 2,01 \times 10^{-5}$ \\
$\mathrm{~L} \mathrm{D} / \mathrm{mol} \mathrm{L}^{-1}$ & $6,71 \times 10^{-7}$ & $8,05 \times 10^{-7}$ & $4,02 \times 10^{-7}$ & $9,39 \times 10^{-8}$ \\
Sensibilidade / $\mathrm{mol} \mathrm{L}^{-1} \mathrm{~cm}^{-1}$ & $5,25 \times 10^{4}$ & $2,09 \times 10^{3}$ & $1,42 \times 10^{3}$ & $5,22 \times 10^{4}$ \\
F A / det h ${ }^{-1}$ & 38 & 11 & 50 & 45 \\
R S D \% & 1,5 & - & 1,2 & 1,0 \\
\hline
\end{tabular}

\section{CONCLUSÃO}

O método proposto em fluxo envolvendo multicomutação e longo caminho óptico para a determinação de cloro em amostras de água de abastecimento mostrou-se promissor, apresentando resultados satisfatórios, quando comparado ao método usado pelas estações de tratamento de água, inclusive o da CETESB (kit DPD-colorimétrico). A célula de longo caminho óptico $(100 \mathrm{~cm})$ proporcionou obter menor limite de detecção, menor consumo de reagente $(0,26 \mu \mathrm{g}$ por determinação) e, conseqüientemente, baixo volume de efluente $(60 \mu \mathrm{L}$ por análise). A multicomutação permitiu o emprego mais adequado da o-Tolidina, pois somente a quantidade necessária desse reagente foi empregada.

\section{AGRADECIMENTOS}

Ao CNPq, à CAPES e FAPESP pelo apoio financeiro obtido.

\section{REFERENCIAS}

1. Cubillos, A.; Calidad y Control de La Polucion del Água. Mérida, CIDIAT/Centro Interamericano de Desarollo Integral de Águas y Tierras, (Mimeo) Série Ambiente y Recursos Naturales Renovables, AR 14, 1981.

2. Hespanhol, I.; Azevedo Netto, J. M.; Botelho, M. H. C.; Revista DAE 1982, 130

3. Oliveira, A. F.; Dissertação de Mestrado, Universidade Federal de São Carlos, Brasil, 1996.

4. Degrémont, G. C.; Water Treatment Handbook, John Wiley \& Sons: New York, 1979.

5. Leme, F. P.: Teoria e Técnica de Tratamento de Água, ABES: Rio de Janeiro, 1979.

6. Bem-Hur, L. B.; Águas, Saúde e Desinfecção, apostila da CETESB, disponível em http://biblioteca.cetesb.sp.gov.br, acessada em Janeiro
2008.

7. Lavorante, A. F.; Feres, M. A.; Reis, B. F.; Spectrosc. Lett. 2006, 39, 631.

8. Lei, W.; Fujiwara, K.; Fuwa, K.; Anal. Chem. 1983, 55, 951.

9. Melchert, W. R.; Rocha, F. R. P.; Raimundo Jr., I. M.; Reis, B. F.; Quim. Nova 2008, 31, 427

10. Pappas, A. C. H.; Stalikas, C. D.; Fiamegos,Y. C.; Karayannis, M. I.; Anal. Chim. Acta 2002, 455, 305.

11. Lupetti, K. O.; Rocha, F. R. P.; Fatibello-Filho, O.; Talanta 2004, 62, 463.

12. Stellman, C. M.; Ewing K. J.; Bucholtz, F.; Aggarwal, I. D.; Sens. Actuators, B 1998, 53, 173

13. Bonifácio, V. G.; Figueiredo-Filho, L. C.; Marcolino-Jr, L. H.; FatibelloFilho, O.; Talanta 2007, 72, 663.

14. Yao, W.; Byrne, R. H.; Talanta 1999, 48, 277.

15. Collins, G. E.; Lu, Q.; Pereira, N.; Wu, P.; Talanta 2007, 72, 301.

16. Waterbury, R. D.; Yao, W.; Byrne, R. H.; Anal. Chim. Acta 1997, 357, 99.

17. Callahan, M. R.; Rose, J. B.; Byrne, R. H.; Talanta 2002, 58, 891.

18. Gimbert, L. J.; Worsfold, P. J.; Anal. Chem. 2007, 26, 914.

19. Zang, J.; Anal. Sci. 2006, 22, 57.

20. www.hach.com/hc/search. product.details.invoker/ PackagingCode $=223101 /$ NewLinkLabel $=$ Chlorine $+\% 28$ Free $+\% 26+$ Total $\% 29+$ Test + Kit $\% 2 \mathrm{C}+$ Model $+\mathrm{CN}-66 \% 2 \mathrm{C}+$ Color + Disc $\% 2 \mathrm{C}+0.1-$ $3.5+\mathrm{mg} \% 26$ fras $1 \% 3 \mathrm{BL} \% 2 \mathrm{C}+100+$ tests/SESSIONID|B3hOVFl6TIRFM k1UWXpNeVpuZFdWemRFTkpWUT09QTFOWU1USQ==|, acessada em Janeiro 2008.

21. Bland, J. M.; Altman, D. G.; The Lancet 1995, 346, 1085.

22. Pobozy, E.; Pyrzynska, K.; Szostek, B.; Trojanowicz, M.; Microchem. J. 1995, 51, 379.

23. March, J. G.; Gual, M.; Simonet, B. M.; Talanta 2002, 58, 995.

24. Icardo, M. C.; Mateo, J. V. G.; Martinez-Catalayud, J.; Anal. Chim. Acta 2001, 443, 153. 